\title{
Percepção das gestantes em relação à assistência pré-natal nas Unidades Básicas de
}

\section{Saúde}

\author{
Perception of pregnant women in relation to prenatal care in basic health units
}

Percepción de la mujer embarazada en relación con la atención prenatal en unidades básicas de salud

Recebido: 27/07/2021 | Revisado: 31/07/2021 | Aceito: 04/08/2021 | Publicado: 10/08/2021

\author{
Joelma dos Santos \\ ORCID: https://orcid.org/0000-0003-4999-0466 \\ Universidade do Estado da Bahia, Brasil \\ E-mail: Joelma gbi10@gmail.com \\ Paloma Carvalho Dias \\ ORCID: https://orcid.org/0000-0002-3397-1925 \\ Universidade do Estado da Bahia, Brasil \\ E-mail: pcdpaloma@gmail.com
}

\begin{abstract}
Resumo
O presente estudo objetivou compreender a percepção das gestantes em relação a assistência pré-natal nas Unidades Básicas de Saúde. Trata-se de um estudo qualitativo de caráter descritivo, realizado com gestantes em acompanhamento de Pré-Natal na Atenção Primaria a Saúde de um município do interior da Bahia. A coleta de dados foi feita através de uma entrevista semiestruturada com roteiro composto por questões que versavam sobre o tema, após assinatura do Termo de Consentimento Livre e Esclarecido. Para análise de dados foi utilizada a técnica de Análise de Conteúdo Temático proposta por Bardin. A pesquisa respeitou os aspectos éticos e científicos de acordo com a Resolução no 466 de 2012 e no 510/16 do Conselho Nacional de Saúde. Por meio da análise do conteúdo, os resultados foram agrupados em três categorias estruturadas: A percepção da gestante quanto a assistência pré-natal recebida; A assistência prestada pela enfermeira (o) e a sua contribuição para o processo de enfrentamento das mudanças relacionadas à gravidez; A consulta de enfermagem e a assistência psicossocial como contribuintes para um pré-natal bem-sucedido. Compreende-se que diante as percepções das gestantes, a assistência prestada pelo (a) enfermeiro (a) no programa pré-natal contempla o acolhimento, ações de cuidado, procedimentos e escuta ativa das mesmas, abrange, sobretudo, a individualidade de cada gestante durante a consultas, e os aspectos biopsicossociais inerentes ao contexto de vida que estão inseridas.
\end{abstract}

Palavras-chave: Gravidez; Assistência pré-natal; Atenção Primária à Saúde; Assistência de enfermagem.

\begin{abstract}
This study aimed to understand the perception of pregnant women in relation to prenatal care in Basic Health Units. This is a qualitative descriptive study, carried out with pregnant women undergoing prenatal care in the Primary Health Care of a municipality. from the interior of Bahia. Data collection was done through a semi-structured interview with a script composed of questions about the theme, after signing the Informed Consent Term. For data analysis, the Thematic Content Analysis technique proposed by Bardin was used. The research respected the ethical and scientific aspects in accordance with Resolution No. 466 of 2012 and No. 510/16 of the National Health Council. Through content analysis, the results were grouped into three structured categories: The pregnant woman's perception of prenatal care received; The care provided by the nurse (o) and her contribution to the process of coping with changes related to pregnancy; Nursing consultation and psychosocial assistance as contributors to successful prenatal care. It is understood that, given the perceptions of pregnant women, the care provided by the nurse in the prenatal program includes the reception, care actions, procedures and active listening to them, covering, above all, the individuality of each pregnant woman during consultations, and the biopsychosocial aspects inherent to the context of life in which they are inserted.
\end{abstract}

Keywords: Pregnancy; Prenatal care; Primary Health Care; Nursing care.

\section{Resumen}

El presente estudio tuvo como objetivo comprender la percepción de las gestantes en relación a la atención prenatal en Unidades Básicas de Salud, se trata de un estudio descriptivo cualitativo, realizado con gestantes en atención prenatal en Atención Primaria de Salud de un municipio del interior de Bahía. La recolección de datos se realizó a través de una entrevista semiestructurada con un guión compuesto por preguntas sobre el tema, previa firma del Término de Consentimiento Informado. Para el análisis de los datos se utilizó la técnica de Análisis de Contenido Temático 
propuesta por Bardin. La investigación respetó los aspectos éticos y científicos de acuerdo con la Resolución $\mathrm{N}^{\circ} 466$ de 2012 y N $^{\circ}$ 510/16 del Consejo Nacional de Salud. A través del análisis de contenido, los resultados se agruparon en tres categorías estructuradas: La percepción de la gestante sobre los cuidados prenatales recibidos. La atención brindada por la enfermera (o) y su contribución al proceso de afrontamiento de los cambios relacionados con el embarazo; La consulta de enfermería y la asistencia psicosocial como contribuyentes al éxito de la atención prenatal. Se entiende que, dadas las percepciones de las gestantes, la atención brindada por la enfermera en el programa prenatal incluye la recepción, acciones de atención, trámites y escucha activa de las mismas, abarcando, sobre todo, la individualidad de cada gestante durante las consultas, y los aspectos biopsicosociales inherentes al contexto de vida en el que se insertan.

Palabras clave: El embarazo; Cuidado prenatal; Primeros Auxilios; Cuidado de enfermera.

\section{Introdução}

A gestação é um período que compreende aproximadamente nove meses de grandes mudanças físicas e físiológicas no corpo da mulher, para assim promover adaptações e desenvolvimento favoráveis a um novo ser, que vão desde alterações psicológicas, causando uma tempestade de sentimentos na mulher, até impactos emocionais, culturais e sociais, ora positivos, ora negativos (Gandof et al., 2019).

Segundo Melo, Silva, Matos e Martins (2020) o planejamento anterior à gravidez, a relação familiar, o meio socioeconômico e cultural, além das experiências gestacionais anteriores, número de filhos, religião, entre outros, são fatores contribuintes pelo modo em que a gestante irá responder às mudanças da gestação. Tais autores ressaltam ainda que a falta de conhecimento da gestante, relacionada às mudanças do momento em que vivencia a gravidez, exige mais atenção e cuidado do profissional durante a consulta de pré-natal.

Diante disso, o programa de pré-natal tem por objetivo acompanhar e garantir o desenvolvimento de uma gestação saudável, a fim de possibilitar um parto tranquilo e um recém-nascido saudável, assegurando a saúde materna em todo processo. Ademais, as consultas de pré-natal devem contemplar aspectos psicossociais, atividades educativas e preventivas em seu contexto (Brasil, 2013).

Nessa perspectiva, a Portaria $n^{\circ} 570$ de $1^{\circ}$ de junho de (2000) e o Ministério da Saúde, preconiza que a primeira consulta de Pré-Natal deve ser iniciada até o $4^{\circ}$ mês de gestação sendo, de preferência, uma no primeiro, duas no segundo e três no terceiro trimestre de gestação respectivamente, totalizando no mínimo seis consultas de acompanhamento Pré-Natal. (Brasil, 2000)

Rosa, Silveira e Costa (2014) citam ainda que a adesão das gestantes no programa de pré-natal contribui para a redução das taxas de morbimortalidades materno-infantil, baixo peso ao nascer e retardo do crescimento intrauterino. Apesar da adesão ao acompanhamento de pré-natal ser um fator facilitador do processo de enfrentamento das alterações do período, apenas as questões centradas no cuidado biológico não são suficientes, sendo de suma importância a inclusão da abordagem dos aspectos psicossociais durante as consultas, uma vez que a vivência da gravidez é fortemente influenciada pelo contexto social (Leite et al., 2014).

Nesse sentido, o Ministério da Saúde traz no caderno da Atenção Básica que o profissional deve promover uma escuta ativa da gestante e de seus (suas) acompanhantes, considerando aspectos intelectuais, emocionais, sociais e culturais e não somente um cuidado biológico (Brasil, 2013). Dessa forma, Souza, Bussadori, Ayres, Fabbro e Wernet (2020, p.2) reforçam que "a integralidade é um princípio doutrinário do Sistema Único de Saúde -SUS ”, e a mulher é tida como um ser com suas particularidades, e nesse sentido, o conceito de integralidade deve estar incluído na assistência do profissional durante as consultas de Pré-natal, tanto nas dimensões biológica quanto psicoemocional, sociocultural e físico-ambiental.

Diante do exposto Gonçalves, Urasaki, Merighi e D`Avila (2008) ressaltam ainda que é possível identificar problemas de saúde e monitorar desempenho da assistência através da avaliação da qualidade do pré-natal, sendo os resultados obtidos de tal avaliação instrumentos que poderão contribuir, tanto para a manutenção das estratégias, quanto para a sua modificação, com 
objetivo de melhora na qualidade da assistência. E nessa perspectiva Prudêncio e Mamede (2018) trazem resultados de pesquisa que revelam a importância da averiguação da expectativa e satisfação da gestante relacionadas a assistência de prénatal.

Por tudo que foi evidenciado, esse estudo parte de uma vivência e percepção pessoal da autora, no qual percebeu falhas no acolhimento e na abordagem dos aspectos psicossociais, o que, consequentemente impactou negativamente no estabelecimento do vinculo com a enfermeira durante o próprio acompanhamento de pré-natal, na unidade básica de saúde.

Contudo, ressalta-se que são escassas as pesquisas sobre a percepção de mulheres gestantes referentes ao atendimento recebido nas consultas de pré-natal e, das pesquisas existentes, há uma lacuna sobre questões que abordem os estados psicossociais das mesmas.

Além disso, percebe-se a relevância científica e social da temática aqui apresentada, o que justifica a realização do presente estudo, que tem como objetivo geral, compreender a percepção das gestantes em relação à assistência Pré-Natal realizada nas unidades básicas de saúde, cujo objetivo específico é discutir se essa assistência contempla os aspectos psicossociais ou se estão centralizados apenas nas mudanças fisiológicas e acompanhamento das mesmas durante o período gestacional.

Diante disso, surge a questão norteadora do estudo: Qual a percepção das gestantes em relação á assistência de PréNatal realizada nas unidades básicas de saúde?

\section{Metodologia}

Trata-se de um estudo qualitativo de caráter descritivo realizado com mulheres gestantes em sete (7) Unidades Básicas de Saúde em um município na região sudoeste do estado da Bahia. Essas Unidades foram escolhidas por terem as maiores populações adstritas do Município e por terem no período várias gestantes em acompanhamento de pré-natal. A condução e apresentação desta pesquisa seguiram os critérios definidos pelo Consolida ted Criteria for Reporting Qualitative Research (COREQ).

Por meio de contato telefônico, foi realizado o agendamento do dia e horário através das (os) enfermeiras (os) coordenadores de cada Unidade de Saúde para coleta de dados com as gestantes. Para inclusão das participantes, utilizaram-se os seguintes critérios: Ser maior de 18 anos, ter realizado no mínimo três (3) consultas de pré-natal com a enfermeira da unidade, aceitar e ter disponibilidade para participar da pesquisa.

E como critérios de exclusão: Não residirem no território da UBS, realizarem pré-natal no serviço particular simultaneamente, e que estivessem com sintomas gripais, como medida preventiva para evitar a contaminação pela COVID19.

A coleta de dados acorreu entre maio e junho de 2021, nas salas de espera das unidades básicas de saúde, as mulheres eram abordadas com explicações a respeito do objetivo da pesquisa. Assim, durante a coleta de dados, utilizou-se a entrevista semiestruturada, com roteiro composto por questões que versavam sobre o tema.

As entrevistas foram gravadas com uma média de duração de seis minutos por consentimento das participantes. A quantidade de participantes foi de 21 gestantes, porém de acordo com o critério de saturação dos dados apenas 17 gestantes foram incluídas no estudo (Nascimento et al.,2018).

Para análise dos resultados, as falas foram transcritas na íntegra e analisadas conforme a análise do conteúdo proposta por Bardin, que se fundamenta em intervenções de desmembramento do escrito em unidades para, dessa forma, encontrar os distintos núcleos de significados que estabelecem o entendimento, e consequente, categorização, que teve como critérios: homogeneidade, pertinência e objetividade (Bardin, 2011), em seguida os dados foram interpretados e analisados de maneira reflexiva com base na literatura existente. 
Para manutenção do sigilo e anonimato das respondentes, adotou-se as denominações G, seguido de algarismos ordinais crescentes conforme ordem de entrevistas. Os arquivos gravados foram guardados e só serão excluídos após cinco anos de acordo com as Resoluções do Conselho Nacional de Saúde $n^{\circ}$ 446/12 e $n^{\circ}$ 510/16 que versam sobre estudos envolvendo seres humanos.

Com vistas a garantir o cumprimento de todos os aspectos éticos e legais que abrangem a investigação com envolvimento de seres humanos, é fundamental citar que as participantes assentiram a participação na pesquisa de forma voluntária mediante assinatura de Termo de Consentimento Livre e Esclarecido (TCLE), além disso, a pesquisa foi submetida ao Comitê de Ética em Pesquisa da Universidade do Estado da Bahia- UNEB, sob CAAE de nº 41227120.6.0000.0057, sendo aprovada mediante parecer $\mathrm{n}^{\mathrm{o}} 4.546 .095$ de 18 de Fevereiro de 2021.

\section{Resultados e Discussão}

O estudo contou com o total de 17 gestantes, cuja caracterização se encontra a seguir: apresentaram faixa etária de 18 a 34 anos, sendo a média de idade 28,8 anos; com relação ao trimestre gestacional duas $(11,76 \%)$ estavam no primeiro trimestre, oito $(47,05 \%)$ no segundo trimestre e sete $(41,17 \%)$ no terceiro trimestre; quanto ao nível de escolaridade foi bem variante, em que sete $(41,17 \%)$ referiram ter completado o ensino médio, quatro $(23,52 \%)$ haviam completado o ensino superior e seis $(35,29 \%)$ evadiram da escola; no que tange à religião $13(76,47 \%)$ se referiram como católicas, três $(17,64 \%)$ como evangélicas e uma $(5,88 \%)$ disse não seguir nenhuma religião.

Houve uma predominância da raça/cor em que $16(94,11 \%)$ respondentes se autodeclararam negras, e uma $(5,88 \%)$ se autodeclarou branca; em se tratando da renda familiar $12(70,58 \%)$ declararam renda familiar igual a um salário mínimo, três $(17,64 \%)$ afirmaram possuir renda maior que dois salários mínimos e duas $(11,76 \%)$ disseram possuir renda familiar maior que três salários mínimo; a respeito do estado civil nove $(52,94 \%)$ respondentes são casadas, seis $(35,29 \%)$ possuem união estável e duas (11.76\%) são solteiras; buscou-se caracterizar as participantes quanto aos antecedentes obstétricos também, e os resultados trazem que nove $(52,94 \%)$ das gestantes eram primigestas, seis $(35,29 \%)$ multigestas e quatro $(23,52 \%)$ já haviam sofrido aborto espontâneo.

As características sociodemográficas das gestantes deste estudo demonstraram baixo nível socioeconômico e predominância da raça/cor parda, tais achados reforçam resultados semelhantes de Corrêa, Tsunechiro, Lima e Bonadio (2014) e Rodrigues, Rodrigues, Ferreira, Pereira e Barbosa (2016) no qual houve prevalência de mulheres pardas, jovens, com companheiro fixo, sem renda fixa e pouco escolarizadas acompanhadas no pré-natal nas Unidades Básicas de Saúde.

Em se tratando dos antecedentes obstétricos os resultados evidenciaram que algumas gestantes estavam vivenciando a primeira gestação e outras já tinham filhos nascidos vivos. Diante disso, Zanatta, Pereira e Alves (2017) trazem que a chegada de um filho é sempre algo novo, porém, devido às intensas mudanças do período é comum que as primigestas tenham sentimentos dicotômicos (positivos e negativos) com relação à gestação.

Apesar de não haver porcentagem significativa para o antecedente de abortamento, de acordo Francisco, Mattar, Bortoletti e Nakamura (2014), faz-se necessário destacar as complicações oriundas do mesmo, além dos impactos psicológicos, como medo de sofrer um novo abortamento e percepções de incapacidade para gerar um filho saudável na gestação atual.

Por meio da análise do conteúdo, os resultados foram agrupados em três categorias estruturadas. Na primeira categoria: "A percepção da gestante quanto a assistência pré-natal recebida", são apontados fatores relacionados ao modo em que a paciente percebe e interpreta o acolhimento, ações de cuidados, avaliações físicas e orientações durante a consulta de pré-natal.

A segunda categoria: "A assistência prestada pela enfermeira (o) e a sua contribuição para o processo de enfrentamento das mudanças relacionadas à gravidez", discute-se a assistência com ênfase nas orientações sobre as mudanças 
fisiológicas do corpo no primeiro, segundo e terceiro trimestre, além de orientação e preparação para parto, puerpério e cuidados com recém-nascido.

A terceira e última categoria versa sobre "A consulta de enfermagem e a assistência psicossocial como contribuintes para um pré-natal bem-sucedido", sendo essas associadas à percepção de um espaço para sanar dúvidas, expressar emoções, medos, angústias, e inclusão das questões psicológicas durante a consulta.

A seguir serão discutidas as categorias oriundas a partir das falas das entrevistadas:

\subsection{A percepção da gestante quanto a assistência pré-natal recebida}

Para Gaiva, Palmeira e Mufato (2017) a percepção se baseia em uma interpretação e experiência positiva ou negativa vivenciada. E de acordo com as falas das gestantes com histórico obstétrico, observa-se que as mesmas chegavam às unidades com baixa expectativa com relação ao atendimento por já criarem um alto nível de satisfação nas consultas anteriores. Assim, Andrade, Castro e Silva (2016) contemplam que esse sentimento de satisfação se deve ao fato de o profissional abordar as questões biopsicossociais durante o acolhimento.

\section{“[...] eu vou tranquila ela [enfermeira] é maravilhosa sempre me atendeu muito bem.” (G17) \\ “[...] Não tenho nenhuma expectativa, porque lá o atendimento é ótimo." (G9) \\ "[...] Fui bem acolhida, não tive nenhum problema com relação a consulta ela [enfermeira] foi solicita naquilo que eu perguntei, soube responder com tempo aquilo que era duvida minha, o que ela [enfermeira] não sabia ela [enfermeira] procurou quem pudesse me orientar ou me responder." (G2)}

Diante das falas, percebe-se que o acolhimento por parte do (a) enfermeiro (a) é a peça chave, tanto para a criação de vínculo com a gestante, quanto para o sucesso de uma assistência qualificada. Desta forma, Ferreira, Melo, Araújo, Melo e Andrade (2017) e Rodrigues et al. (2021) enfatizam que a integralidade do cuidado contribui para uma assistência humanizada e tem uma grande relevância sobre a redução da mortalidade materno-infantil. Sendo assim, a competência do (a) enfermeiro (a) de realizar uma consulta integral independente do trimestre de gravidez. Porém, comumente prioriza-se muito a integralidade na primeira consulta, todavia as consultas subsequentes são mais superficiais, mas, é fundamental que a totalidade das consultas seja pautada na assistência global da gestante.

Quando perguntadas acerca da estruturação das consultas, as mesmas inferiram sobre as ações e procedimentos realizados, o que está demonstrado nas seguintes falas:

"Primeiro se tiver exames ele [enfermeiro] vai olhar e anota tudo na caderneta, pesa, mede a barriga, pega na barriga pra ver o bebê, escuta o coração, afere a pressão, olha os exames e recomenda sobre a alimentação, se tiver que tomar algum medicamento tudo ele passa, tem todo cuidado em questão do repelente para proteger dos mosquitos, ele recomenda essas coisas assim."(G9)

"Ela [enfermeira] conferiu os resultados de exame, fez os testes rápidos e o teste da mamãe, preencheu a caderneta da gestante me explicou tudo como funcionava pediu os exames, passou o ácido fólico pra ir tomando, depois pediu uma ultrassom pelo SUS e a princípio foi isso, tirou algumas dúvidas minhas que eu estava a respeito". (G8) 
É predominante, na fala das participantes, que as condutas realizadas pelo (a) enfermeiro (a) se baseiam em conhecimento teórico-científico. Diante disso, de acordo Oliveira, Babosa e Melo (2016), é imprescindível a realização das ações como: exame físico da gestante, avaliação e orientação nutricional, medidas antropométricas, sinais vitais, batimentos cardíacos fetais, prescrição de medicamentos (ácido fólico, sulfato ferroso).

Além, dos Testes rápidos (vírus da imunodeficiência humana (HIV), hepatite B, sífilis, hepatite C; Triagem neonatal em papel filtro; Solicitação/interpretação de exames laboratoriais (tipagem sanguínea com fator Rh, Coombs indireto/se Rh negativo, hemograma, eletroforese de hemoglobina, glicemia, sumario de urina e urocultura, toxoplasmose, sífilis (VDRL), hepatite B (HBsAg); de Imagem (ultrassonografia obstétrica), e além das vacinas (antitetânica, hepatite B, Influenza); se tiver indicação clínica, realizar citopatológico de colo de útero e parasitológico de fezes (Brasil, 2013).

Frente a essas percepções, a realização desses procedimentos, intervenções e orientações durante a consulta de prénatal, são extremamente necessárias para a averiguação da saúde do binômio mãe-filho, além da identificação de possíveis problemas que possam comprometer a evolução da gestação, parto e puerpério (Andrade, Castro \& Silva, 2016).

Assim, em concordância aos demais autores, Oliveira et al. (2016) descrevem a suma importância da avaliação e registro na caderneta da gestante de cada dado colhido desde a anamnese do primeiro trimestre até a última consulta. Desta forma, possíveis achados podem ser determinantes para classificar a gestação como de risco, merecendo uma maior atenção especializada. Nesse sentido, observa-se que parte das ações realizadas pelo (a) enfermeiro (a) nas consultas do presente estudo, converge ao que é preconizado pelo ministério da saúde.

\subsection{Assistência prestada pelo (a) enfermeiro (a) e a sua contribuição para o processo de enfrentamento das mudanças relacionadas à gravidez}

O ministério da saúde preconiza que a assistência de enfermagem deve propiciar condições para promoção á saúde da gestante e a melhoria na sua qualidade de vida, mediante uma abordagem contextualizada e participativa. Além de uma escuta qualificada que permita a mulher expressar seus sentimentos relacionados a essa nova fase (Brasil, 2013). A fala a seguir reflete sobre isto:

"[...] quando eu descobri a gravidez eu estava muito insegura, então além de me deixar tranquila em relação a mim ela [enfermeira] também me deixa tranquila em relação a minha filha também.” (G17)

A descoberta da gravidez causa profundos sentimentos na mulher, e diante disso, surgem dúvidas e inseguranças por ter que assumir a maternidade, o papel de mãe. De acordo Zanatta, Pereira e Rubin (2015) a intensidade desses sentimentos depende do meio socioeconômico, situação conjugal e apoio familiar, em especial à participação efetiva do pai da criança.

\section{“[...] antes eu não sabia de nada ai ela [enfermeira] me explicou bastante.” (G15)}

A própria inexperiência das mudanças físicas e fisiológicas do período gestacional gera diversos questionamentos á mulher, por ser algo novo. Nessa perspectiva, a fala da participante G15 demonstra que a carência de informações relacionadas às alterações do período, foram supridas durante as consultas.

Diante disso, uma assistência que forneça informações a mulher sobre a gestação, são evidenciados no estudo de Moura et al. (2015), no qual explicações a respeito do desenvolvimento fetal, autocuidado, mudanças no corpo materno no primeiro, segundo e terceiro trimestre, são preceptores para desencadear a autoconfiança para viver a gestação na sua plenitude. 
Nessa perspectiva, Campus, Veleda, Coelho e Telo (2016) enfatizam que a ações educativas são um dos papeis importantes, e eixo fundamental da pratica dos profissionais de enfermagem que atuam na atenção primária, no contexto da atenção pré-natal.

Assim, de acordo com Gandolfi et al. (2019) a assistência qualificada tem impactos significativos ao longo da gestação, oportunizando a vivência das mulheres, de modo a despreocupá-las em relação á fisiologia do período ao mesmo tempo, levando-as a conduzir a experiência de forma completa e prazerosa.

Seguindo essa mesma lógica é de extrema importância que a assistência contemple ainda informações sobre o ciclo gravídico-puerperal, e adiante as falas representam a forma com que são abordadas essas questões.

"[...] ela [enfermeira] esclarece mais como vai ser tipo, a gravidez, depois que a criança nascer ela fala como vai ser, como tem que dar de mamar pra criança, pra criança ter que alimentar direito, essas coisas ai". (G1)

Através do relato das participantes em relação ao período gestacional, percebe-se que elas estavam ao final do terceiro trimestre de gravidez, esses dados vão de encontro aos resultados do estudo de Gonçalves et al. (2017), no qual houve associação entre as orientações sobre parto e puerpério, e o intervalo de quinze dias para a última consulta de pré-natal.

Diante disso, Tostes e Seidl (2016) e Gonçalves et al. (2017) justificam que o terceiro trimestre traz o sentimento de ansiedade para a mulher, principalmente quando a mesma obtém informações sobre o parto de pessoas leigas, e quando possuem experiências anteriores negativas. Isso implica na formação do medo do trabalho de parto, medo da dor, das contrações e das complicações que possam surgir durante o trabalho de parto.

“[...] eu não tenho o que reclamar, ela [enfermeira] está me ajudando com a questão do psicológico, sobre o parto, pra eu ficar tranquila, calma, pra minha ansiedade não passar para o bebê. Porque eu pensava que meu parto ia ser normal, mas ai a bebê não virou ainda." (G16)

Assim, afirma-se que a resoluta assistência de enfermagem, atrelada às orientações deve ser ofertada a cada oportunidade para as gestantes, sobretudo, no terceiro trimestre, devido à aproximação do momento do parto. E como consequências, tem-se a contribuição singular para o processo de enfrentamento das mudanças relacionadas à gravidez, tornando as gestantes protagonistas de todo o processo, além de promover a autoconfiança e segurança para estas mulheres.

\subsection{A consulta de enfermagem e a assistência psicossocial como contribuintes para um pré-natal bem-sucedido}

A assistência psicossocial remete a ideia de abarcar durante as consultas do programa pré-natal a abordagem e identificação dos aspectos psicossociais daquela mulher, que além de grávida é um ser humano e está inserida em um contexto social com suas particularidades (Silva et al., 2020). Desta forma, a partir das falas, observa-se que os aspectos relacionados ao psicológico (expressão de dúvidas e anseios), e social (núcleo familiar, vinculo social, vínculo com a equipe da unidade de saúde), foram abarcados durante as consultas.

Assim, de certo modo, esses aspectos irão dizer a forma em que a mulher irá responder à gestação. Quando perguntado sobre a existência de um espaço durante as consultas para tirar dúvidas, expressar medos angústias ou alegria as falas foram: 
“[...] Dá sim ela [enfermeira] dá abertura pra eu relatar alguma coisa que eu sinta necessidade”. (G12)

Segundo o Ministério da Saúde a expressão de sentimentos, contexto da gestação e história de vida devem ser permitidos e acolhidos em uma escuta qualificada pelo (a) enfermeiro (a) durante as consultas de pré-natal. Contudo é dever do (a) mesmo (a) buscar entender, de acordo as falas das gestantes, os vários significados daquela gestação para ela, para a sua família e abordar também as questões psicossociais em paralelo (Brasil, 2012).

Em concordância ao exposto, Bortoli et al. (2017), enfatizam que através de um espaço de acolhimento durante as consultas, é possível permitir expressão de sentimentos, dúvidas, experiências, facilitando assim a criação de vínculo entre profissional-paciente. Por ser reconhecida como espaço de acolhimento, a consulta de enfermagem, no âmbito do pré-natal, possibilita e propicia, por meio das condutas e ações, às mulheres a lidar com situações que possam surgir no período da gestação.

“[...] A gente fica com muito medo sabe? Muita dúvida se isso é normal ou se não é, ainda mais quando a gente é mãe solteira e não tem o apoio do parceiro então é mais difícil ainda psicologicamente sabe, então não tenho nada o que queixar eles [equipe da UBS] são ótimos". (G17)

De acordo com a fala, são maiores as dificuldades encontradas em lidar com a gestação quando as mulheres não possuem um parceiro fixo, pois, além das preocupações com a gestação, surgem as preocupações relacionadas à renda e rede de apoio. Essa situação conjugal e socioeconômica é apontada por Souza (2011), como determinante para gerar impactos psicológicos e consequentemente uma possível rejeição ao feto.

Destaca-se também as consequências psicossociais, como a rejeição familiar, sentimento de insegurança, medo e vergonha, bem como perda de autonomia e maiores riscos de depressão e suicídio.

"[...] quando eu descobri minha gravidez eu estava com certo sentimento de rejeição, no início eu não queria e depois da primeira consulta que eu tive com ela eu sai mais aliviada, eu estava com medo de contar para meus pais, aí eu cheguei e consegui contar para meus pais já”. (G7)

A fala da participante revela que a descoberta da gravidez não planejada sem um parceiro fixo, despertou o sentimento de medo para revelar aos pais, e consequentemente um pensamento de não levar adiante a gravidez. Porém, a partir do acolhimento da enfermeira durante a consulta de pré-natal, foi possível reverter esses pensamentos negativos, o que consequentemente gerou a aceitação e assimilação do seu papel na maternidade.

Diante o exposto, para um pré-natal bem-sucedido é preciso que o profissional tenha um olhar individual, considerando cada gestante como um ser único, cujas queixas são particulares e distintas, e não apenas foque a assistência nos cuidados biológicos. Além disso, a escuta do (a) enfermeiro (a) deve ser ativa, livre de julgamentos e preconceitos para cada situação, tendo como ênfase a resolução de problemas identificados (Brasil, 2013).

\section{"[...] ela [enfermeira] me dá espaço, me dá apoio, eu até falo que ela [enfermeira] é uma psicóloga”. (G14)}

Em um estudo de Cunha et al. (2020), os resultados enfatizam que é fundamental uma assistência à saúde mental das gestantes na atenção primaria para identificação de sinais de ansiedade e possível depressão durante o acompanhamento de 
pré-natal, a fim de encaminhar essas mulheres aos profissionais especializados com vistas a evitar futuras consequências ao binômio, contribuindo desta forma para a continuidade do cuidado.

Esses espaços são extremamente importantes para que as mulheres se sintam contempladas com assistência prestada, por isso, a consulta se torna o momento no qual as mesmas têm a oportunidade de relatar dúvida, medo, alegria entre outros sentimentos. Porém, a depender da agenda do (a) enfermeiro (a) naquele dia, e da demanda, esse espaço muitas vezes deixa de ser ofertado pela celeridade da consulta, o que pode caracterizar o atendimento como inadequado (Costa, Vila, Rodrigues, Martins \& Pinho, 2013).

\section{Conclusão}

A partir dos dados das respondentes do presente estudo, compreende-se que diante as percepções das gestantes, a assistência prestada pelo (a) enfermeiro (a) no programa pré-natal contempla o acolhimento, ações de cuidado, procedimentos e escuta ativa das mesmas, e abrange, sobretudo, a individualidade de cada gestante durante as consultas, e os aspectos biopsicossociais inerentes ao contexto de vida que estão inseridas.

Os dados coletados, através da entrevista, apontam que as gestantes percebiam a assistência como adequada para as suas necessidades e tinham espaço e oportunidade de fala garantidos, além de vínculo efetivo com o (a) enfermeiro (a) que a atendeu, diminuindo assim o nível de expectativa.

É importante destacar que a limitação deste estudo está diretamente relacionada à escassez de pesquisas sobre a percepção de mulheres gestantes referentes ao atendimento recebido nas consultas de pré-natal e, sobre questões que abordem os aspectos psicossociais das mesmas durante o acolhimento.

Por isso, aos trabalhos futuros, é válido ressaltar a necessidade do desenvolvimento de pesquisas com maiores populações, para averiguar a percepção das gestantes sobre a assistência, e se, há abordagem dos aspectos psicossociais durante o acolhimento e condução do pré-natal.

Encerra-se este trabalho com o intuito de alertar os profissionais enfermeiros (as) sobre a possibilidade de revisão das consultas pré-natal, a fim de refletir sobre a assistência profissional fornecida para o cuidado às gestantes, favorecendo assim novas reflexões acerca da temática aqui estudada.

\section{Referências}

Andrade, F. M., Castro, J. F. L., \& Silva, A. V. (2016). Percepção das gestantes sobre as consultas médicas e de enfermagem no pré-natal de baixo risco. Enferm. Cent. O. Min. 6(3), 2377-88. 10.19175/recom.v6i3.1015

Bardin, L. (2011). Análise de Conteúdo. Edições 70.

Bortoli, C. F. C., Bisogni, P., Wilhelm, L. A., Prates, L. A., Sehnem, G. D. \& Ressel, L. B. (2017). Fatores que possibilitam a atuação do enfermeiro na atenção pré-natal. Revista Fundação Care Online. 9(4), 978-83. 10.9789/2175-5361.2017.v9i4.978-983

Brasil. Portaria $\mathrm{n}^{\circ} 570$, de $1^{\circ}$ de junho de 2000. Estabelece o programa de humanização no pré-natal e nascimento. Diário oficial da união. http://bvsms.saude.gov.br/bvs/saudelegis/gm/2000/prt0570_01_06_2000_rep.html.

Brasil (2013). Ministério da saúde. Secretaria de atenção à saúde. Atenção ao pré-natal de baixo risco. https://bvsms.saude.gov.br/bvs/publica coes/atencao_pre_natal_baixo_risco.pdf

Campos, M. L., Veleda, A. A., Coelho, D. F., \& Telo, S. V. (2016). Percepção das gestantes sobre as consultas de pré-natal realizadas pelo enfermeiro na atenção básica. J Nurs Health. 6(3), 379-90. https://doi.org/10.15210/jonah.v6i3.7949

Corrêa, M. D., Tsunechiro, M. A., Lima, M. O. P., \& Bonadio, I. C. (2014). Avaliação da assistência pré-natal em unidade com estratégia saúde da família. Rev Esc Enferm USP. 48(Esp), 24-32. https://doi.org/10.1590/S0080-623420140000600004

Costa, C. S. C., Vila, V. C., Rodrigues, F. M., Martins, C. A., \& Pinho, L. M. O. (2013). Características do atendimento pré-natal na rede básica de saúde. Rev. Eletr. Enf. 15(2), 516-22.: https://doi.org/10.5216/ree.v15i2.15635 
Cunha A. C. S., Borges, J. L. F., Ribeiro, M. E. S., Savino, B. A. C., Domingues, G. P., Brega, C. B., Oliveira, C. H. N., \& Brito, D. M.S. (2020). Efeitos psicossociais da gravidez na adolescência: um estudo transversal. Braz. J. of Develop. Curitiba. 6(7), 47412-24. 10.34117/bjdv6n7-395

Ferreira, T. L. S., Melo, F. L. A. C. G., Araujo, D. V., Melo, K. D. F., \& Andrade, F. B. (2017). Avaliação da assistência com foco na consulta de atendimento pré-natal. Revista Ciência Plural. 3(2), 4-15. https://periodicos.ufrn.br/rcp/article/view/12333

Francisco M. F. R., Mattar, R., Bortoletti, F. F., \& Nakamura, M. U. (2014). Sexualidade e depressão em gestantes com aborto espontâneo de repetição. Rev. Bras. Ginecol. Obstet. 36(4), 152-6. 10.1590/s0100-720320140050.0004

Gaíva, M. A. M., Palmeira, E. W. M., \& Mufato, L.F. (2017). Women's perception of prenatal and delivery care in cases of neonatal death. Esc Anna Nery. 21(4), e20170018. 10.1590/2177-9465-EAN-2017-0018

Gandolfi, F. R. R., Gomes, M. F. P., Reticena, k. O., Santos, M. S. \& Damini, N. M. A. V. (2019). Mudanças na vida e no corpo da mulher durante a gravidez. Brazilian jornal of Surgery and Clinical Research-BJSCR. 27(1), 126-31. https://www.mastereditora.com.br/periodico/20190607_200629.pdf

Gonçalves M. F., Teixeira, E. M. B., Silva, M. A. S., Corsi, N. M., Ferrari, R. A. P., Pelloso, S. M., \& Cardelli, A. A. M. (2017). Pré-natal: preparo para o parto na atenção primária à saúde no sul do Brasil. Rev Gaúcha Enferm. 38(3), e2016-0063. https://doi.org/10.1590/1983-1447.2017.03.2016-0063

Gonçalves, R., Urasaki, M. B. M., Merghi, M. A. B., \& D`Avila, C. G. (2008). Avaliação da efetividade da assistência pré-natal de uma Unidade de Saúde da Família em um município da Grande São Paulo. Rev. Bras. Enferm. 61(3), 349-53. https://doi.org/10.1590/S0034-71672008000300012

Leite, M. G., Rodrigues, D. P., Souza, A. A. S., Melo, L. P. T., \& Fialho, A. V. M. (2014). Sentimentos advindos da maternidade: revelações de um grupo de gestantes. Psicologia em Estudo, Maringá. 19(1), 115-24. https://doi.org/10.1590/1413-7372189590011

Melo, D. E. B., Silva, S. P. C., Matos, K. K. C. \& Martins, V. H. S. (2020). Consulta de enfermagem no pré-natal: representações sociais de gestantes. Rev. Enferm. UFSM - REUFSM Santa Maria, RS. 10, e18, 1-18. 10.5902/2179769237235

Moura, S. G., Melo, M. M. M., César, E. S. R., Silva, V. C. L., Dias, M. D., \& Filha, M. O. F. (2015). Assistência pré-natal realizada pelo enfermeiro (a): um olhar da mulher gestante. Revista de pesquisa cuidado é fundamental online. 7(3), 2930-38. 10.9789/2175-5361.2015.v7i3.2930-2938

Nascimento L. C. N., Souza, T. V., Oliveira, I. C. S., Moraes, J. R. M., Aguiar, R. C. B. \& Silva, L. F. (2018). Theoretical saturation in qualitative research: an experience report in interview with schoolchildren. Rev Bras Enferm. 71(1), 228-33. https://doi.org/10.1590/0034-7167-2016-0616

Oliveira, E.C., Barbosa S. M., \& Melo, S. E. P. (2016). A importância do acompanhamento pré-natal realizado por enfermeiros. Revista Científica Fac Mais. 7(3), 24-38 https://revistacientifica.facmais.com.br/wp-content/uploads/2017/01/Artigo-02

Prudencio, P. S. \& Mamede, F. V. (2018). Avaliação do cuidado pré-natal na atenção primária a saúde na percepção da gestante. Rev. Gaúcha Enferm. 39, e20180077. https://doi.org/10.1590/1983-1447.2018.20180077

Rodrigues, A. F. M., Candido, C. L., Campos, G. K. P., Barcellos, J. E. S., Rodrigues, L. A. \& Seidel, T. S. (2021). Pré-natal na atenção primária, adequação das consultas e avaliação da assistência às gestantes: revisão integrativa. Revista Nursing. 24(275), 5484-89. https://doi.org/10.36489/nursing.2021v24i275p5484-5495

Rodrigues, I. R., Rodrigues, D. P., Ferreira, A. S., Pereira, M. L. D., \& Barbosa, E. M. G. (2016). Elementos constituintes da consulta de enfermagem no prénatal na ótica de gestantes. Rev RENE. 17(6), 774-81. 10.15253/2175-6783.2016000600007

Rosa, C. Q., Silveira D. S., \& Costa, J. S. D. (2014). Fatores associados à não realização de pré-natal em município de grande porte. Rev Saúde Pública. 48(6), 977-84. 10.1590/S0034-8910.2014048005283

Silva, G. F. P., dos Santos, S. V., do Nascimento, J. W. A., de Santana, F. S., de Medeiros, J. S., \& de Jesus, S. B. (2020). Risco de depressão e ansiedade em gestantes na atenção primária. Nursing (São Paulo). 23(271), 4961-70. https://doi.org/10.36489/nursing.2020v23i271p4961-4970

Sousa, J. J. (2011). Circunstâncias da ocorrência de gravidez não planejada em mulheres adultas. Universidade Federal da Bahia, (dissertação de mestrado). Escola de Enfermagem. http://repositorio.ufba.br/ri/handle/ri/12740

Souza, B. F., Bussadori, J. C. C., Ayres, J. R. C. M., Fabbro, M. R. C., \& Wernet, M. (2020). Enfermagem e gestantes de alto risco hospitalizadas: desafios para integralidade do cuidado*v. Rev Esc Enferm USP. 54, e03557. https://doi.org/10.1590/S1980-220X2018036903557

Tostes, N. A., \& Seidl, E. M. F. (2016). Expectativas de gestantes sobre o parto e suas percepções acerca da preparação para o parto. Trends in Psychology / Temas em Psicologia. 24(2), 681-93. 10.9788/TP2016.2-15

Zanatta, E., Pereira, R., \& Rubin, C. (2015). "Ela Enxerga em Ti o Mundo": A Experiência da Maternidade pela Primeira Vez. Temas em Psicologia. 23(4), 959-72. 10.9788/TP2015.4-12

Zanatta, E., Pereira C. R. R., \& Alves A. P. (2017). A experiência da maternidade pela primeira vez: as mudanças vivenciadas no tornar-se mãe. Pesqui. Prát. Psicossociais, São João del-Rei. 12(3), e1113. http://www.seer.ufsj.edu.br/index.php/revista_ppp/article/view/2646/1751 